\title{
La captura de la fragata María Isabel. El dilema de los barcos rusos y la independencia de chile*
}

\begin{abstract}
KAREN IsABEL MANZANO ITURRA
Afiliada institucionalmente al Instituto de Historia de la Universidad San Sebastián (Chile). Correo electrónico: karen.manzano@usach.cl. La autora es Doctora en Estudios Americanos por la Universidad de Santiago de Chile. ORCID: https://orcid.org/0000-0002-7069-0698. Entre sus publicaciones recientes tenemos: "Acuífero Guaraní y Patagonia. Gobernanza ambiental desde América del Sur. (1990 - 2017)", Anuario de Historia Regional y de las Fronteras Vol. 25 No. 1 (2019) y en coautoría "El agua del altiplano y su papel en las conversaciones chileno - bolivianas de 1950”, Revista Dialogo Andino No. 61 (2020). Entre sus temas de interés están Geopolítica, Relaciones Internacionales, Fronteras, Historia, Antártica
\end{abstract}

Recibido: 20 de febrero de 2020

Aprobado: 3 de abril de 2020

Modificado: 16 de abril de 2020

Artículo de investigación científica

DOI: https://doi.org/10.15648/hc.39.2021.2966

Este artículo forma parte del proyecto: "La captura de la fragata María Isabel. El dilema de los barcos rusos y la independencia de chile" financiación propia.

Esta publicación está bajo una licencia Creative Commons Reconocimiento-NoComercial 4.0 (c) BY-NC 
La captura de la fragata María Isabel. El dilema de los barcos rusos y la independencia de chile

\title{
Resumen
}

Durante el periodo de la independencia, las acciones marítimas fueron fundamentales en la consolidación de la llibertad, algo que Chile no logró en la Patria Vieja pero si en el gobierno del general O’Higgins, que buscó crear una Armada que fuese capaz de enfrentar las expediciones que llegasen desde la península, destacando la toma de la fragata María Isabel, antigua fragata rusa adquirida por España para recuperar sus colonias. Por medio de una investigación cualitativa, se busca comprender el dilema de los barcos rusos, la relevancia de este hecho en la expedición española de 1818 y la independencia chilena.

Palabras clave: Chile, España, María Isabel, barcos rusos, Armada.

The capture of the Frigate Maria Isabel. The Russian boats dilemma and the independence of Chile

\begin{abstract}
During the period of independence, maritime actions were highly relevant for the consolidation of freedom. Even if Chile did not achieve her independence at the "Patria vieja", the aforementioned country finally succeeded in that process during the government of General O'Higgins. That general sought to create an army able to face enemy expeditions arrived from the peninsula. In this sense, the taking of the "María Isabel" frigate — ancient Russian frigate acquired by Spain to regain their colonies - is a fundamental, but less known episode in Chilean naval history. By means of a qualitative research, we seek to understand the importance to Chilean independence of the "Russian Ships Dilemma" to adequately ponder the Spanish expedition of 1818 towards Chile.
\end{abstract}

Keywords: Chile, Spain, María Isabel, Russian boats, Navy.

\section{A captura da fragata Maria Isabel. O Dilema dos barcos russos e a independência do Chile}

Resumo

Durante o período da independência, ações marítimas foram determinantes para a consolidação da liberdade, algo que o Chile não conseguiu na velha pátria, mas 
sim no governo do general O’Higgins, que procurou criar um exército que seria capaz de enfrentar as expedições que chegaram da península, enfatizando a decisão de tomar o navio Maria Isabel, antiga fragata russa adquirida pela Espanha para recuperar suas colônias. Através de uma pesquisa qualitativa procura-se entender o dilema dos navios russos, a relevância deste fato na expedição espanhola de 1818 e da independência chilena.

Palavras-chave: Chile, Espanha, Maria Isabel, russos barcos da Marinha.

\section{La capture de la frégate María Isabel. Dilemme des bateaux russes et l'independance du chili}

\section{Résumé}

Pendant la période d'indépendance, les actions maritimes furent fondamentales dans la consolidation de la liberté, quelque chose que le Chili n'a pas réussi dans la Patria Vieja mais sí dans le gouvernement du général o 'Higgins, qui visait à créer une armée qui serait en mesure d'affronter les expéditions qui sont arrivés de la péninsule, mettant l'accent sur la décision de prendre la frégate Maria Isabel, ancienne frégate russe acquise par l'Espagne pour regagner ses colonies. Grâce à une recherche qualitative on essaie de comprendre le dilemme des navires russes, la pertinence de cet événement dans l'expédition espagnole de 1818 et l'indépendance chilienne.

Mots cles: Chili, Espagne, Maria Isabel, bateaux russes, marine.

\section{INTRODUCCIÓN}

En 1810, la Primera Junta Nacional de Gobierno realizada en Santiago de Chile decidió mantener el gobierno en nombre del rey de España, facilitando la creación del Congreso Nacional, pero en un ambiente en donde se conjugaban dos visiones de futuro: una moderada en torno a los partidarios del rey Fernando VII y una exaltada que buscaba la libertad. Al año siguiente los acontecimientos se sucedieron rápidamente, y la llegada de José Miguel Carrera significó el quiebre, se declaró la independencia y comenzó la Patria Vieja. En una ofensiva militar enviada desde el Virreinato de Perú para volver al régimen colonial, las tropas llegaron por mar, recalando en Chiloé y Valdivia, para comenzar 
la invasión por Talcahuano. En ese entonces no se logró evitarlo, ya que Chile no poseía barcos para su defensa. Aunque existió un breve atisbo de formación de una Armada como tal, este finalizó en el combate de Valparaíso (1813) cuando el Potrillo y la Perla (el primero adquirido y el segundo arrendado por parte de Chile) se enfrentaron a la Warren, una fragata española, siendo esta última quien se alzó con la victoria cuando logran sublevar a la tripulación de la Perla. Con ello, el poderío marítimo se perdió, algo que fue notorio especialmente por que las fuerzas realistas siempre contaron con apoyo para mantenerse en la guerra. Mientras tanto, el gobierno chileno no obtuvo el control del mar y se enfrentó a un enemigo que logró el triunfo logístico antes que en el campo de batalla, terminando sus principales líderes asilados en Mendoza.

Esto cambió tres años más tarde. El triunfo del Ejercito de los Andes, que cruzó la cordillera y derribó al gobierno de Casimiro Marcó del Pont luego de la batalla de Chacabuco, contaba con una nueva visión. Bernardo O’Higgins, quien tras la victoria asumió como Director Supremo, comprendió desde el primer momento que era vital el dominio marítimo para mantener la existencia de la República, aun frágil, ya que existían focos de resistencia en la zona sur del territorio. Para ello, enfocó sus esfuerzos para sumar una nueva institución en el país, que complementara las funciones del Ejército, preocupándose de vigilar el mar y protegerlo del enemigo que, aun en Lima, estaba dispuesto a seguir extendiendo la guerra. En esa visión, influían los conocimientos que el nuevo Director Supremo había adquirido en su formación en Inglaterra, en momentos que comenzaba su despegue a potencia mundial y que viviendo en una isla, comprendieron el mar no como enemigo sino como parte de su identidad.

Influenciado por tales pensamientos y consciente de ello, se redactan los primeros decretos en torno a la nueva formación de la Armada de Chile, pero también se comienzan a preparar para los nuevos combates 266 que se avecinan. Por otra parte, en Europa, una España saliente de guerras e invasiones se aprestaba a iniciar una gran expedición para recuperar sus colonias, en medio de un clima de restauración de la 
monarquía absolutista de Fernando VII y en búsqueda de apoyos en los vencedores de Napoleón.

En el presente artículo, mediante una metodología cualitativa que utilizará fuentes primarias (archivos y documentos de época) secundarias (libros de autores posteriores) y terciarias (prensa oficial) se analizará las acciones en torno al combate de Talcahuano, cuando se enfrentará la Armada de Chile frente a las fuerzas españolas, en medio de las discusiones en torno a las nuevas capacidades de la institución e inmersas en el discurso de la flota rusa que compró España, los cuales han pasado a la historia en torno a sus capacidades para hacer frente a un enemigo superior.

\section{LA INDEPENDENCIA Y EL DOMINIO DEL MAR}

Durante el periodo de la Independencia, y especialmente tras el triunfo de Chacabuco, se comprendió la importancia del mar. En palabras del propio Director Supremo, Bernardo O’Higgins, que exclamó "Este triunfo y cien más serán insignificantes si no dominamos el mar", se demostró con claridad su pensamiento geopolítico, cuya relevancia estaba concentrada en el control del mar y la zona austral - antártica. Bajo esta perspectiva, el dominio del mar significaba cortar las comunicaciones del enemigo, que por vía marítima había comprendido sus capacidades derrotando a los chilenos en el periodo de la Patria Vieja, ya que logísticamente logró articular el transporte de las tropas para tomar uno a uno los principales puertos y en su interior, las ciudades del país. Por ello se comprende que:

"El nacimiento de nuestro poder naval fue producto de esa clara visión geopolítica y de la imaginación de estadista del Libertador O’Higgins. Inmediatamente después de fundar la República, creó la Escuela Naval y la Primera Escuadra nacional. Este concepto naval fue germinando en él desde su niñez, con la experiencia de una vida de estudiante dentro y fuera del país"1.

1 Jorge Iturriaga, “Bernardo O’Higgins, Lord Cochrane y el Mar de Chile”, Revista Libertador O’Higgins Vol. 1 (2010): 355 
Para O’Higgins fue necesario cortar las comunicaciones del Virreinato del Perú, que estaba enviando tropas para seguir atacando a las fuerzas patriotas. Una de las primeras acciones ejecutadas fue comenzar a trabajar en las instituciones necesarias para que el poderío naval se consolidara, para ello se hizo necesario una serie de conversaciones para adquirir fondos para la compra de buques que defendieran el nuevo gobierno chileno. Una de las primeras acciones fue realizada por Bernardo O’Higgins, que consiguió 100.000 pesos de la época para la adquisición de buques en el extranjero, principalmente en Estados Unidos, donde compró la Independencia y el Araucano, mientras que en Inglaterra se adquirió el Lautaro y San Martín ${ }^{2}$ que junto a la Chacabuco formaban la incipiente primera Escuadra Nacional, entre 1817 y 1818.

Unido a ello, se conformó una serie de decretos que apuntan a cimentar la nueva Armada de Chile. El primero de ellos nació en octubre de 1817, como la Comandancia General de Marina y al mes siguiente el Reglamento Provisional de Marina, que regulaba los sueldos y grados de la institución:
"Entonces, en enero de 1818, las autoridades nombraron como coman- dante de Marina interino a Juan José Tortel, función que desde octubre de 1817 hasta ese momento ejercía el gobernador civil y militar de Valpa- raíso. Como la actividad naval iba en aumento, el gobierno resolvió ordenar al comandante de Marina que elaborara un presupuesto para adquirir pertrechos navales y almacenarlos en un arsenal. El decreto respectivo hace algunas consideraciones sobre la necesidad de dominar el Pacífico como justificación del gasto en que se iba a incurrir"3.

Entre los primeros integrantes se contaban a marinos extranjeros, como Juan José Tortel (de origen francés) y para suplir estas deficiencias en cuanto a capital humano nacional fue necesaria la creación de una escuela matriz para la formación de oficiales, naciendo la Academia de Jóvenes Guardiamarinas, el 04 de agosto de 1818. Además de la necesidad de recursos humanos, un serio problema fue conseguir dinero para el

2 Renato Valenzuela, Bernardo O’Higgins. El Estado de Chile y el poder naval en la independencia de los países del sur de América (Santiago: Editorial Andrés Bello, 2008).

3 Armada de Chile. Escuadra Nacional 1818 - 2018. Santiago. Ograma Editores. 2018, 37 
financiamiento y la formación de la Escuadra, debida a que producto de la guerra se había afectado seriamente la economía, principalmente agrícola y ganadera de la zona central, unida a las exiguas ganancias obtenidas en la minería del cobre del Norte Chico. Por ello, el gobierno chileno creó nuevos impuestos para aumentar el gravamen fiscal, pero que generaban molestias dentro de la aristocracia local. Tras ello, se comprende que:

“En la adquisición de buques se invirtió la suma de $\$ 616.00043$, aunque si se agregan las comisiones de los agentes e intermediarios, los gastos incurridos por el buque a vapor Estrella Naciente que, finalmente, no se incorporó, los pagos de las tripulaciones que traían los buques desde puertos extranjeros antes de entrar a la Escuadra y los desembolsos que demandó armarlos y apertrecharlos cuando llegaban como buques mercantes, que era lo normal, es posible que esta cifra se haya elevado hasta los $\$ 700.000$ señalados por el general argentino Tomás Guido"4.

Los buques adquiridos provenían de diferentes astilleros, los que fueron reforzados por los barcos que fueron confiscados a la empresa libertadora de José Miguel Carrera, quien en Estados Unidos obtuvo apoyo para armas y navíos, pero que fue detenida en Buenos Aires por las autoridades del Río de la Plata. Con ello, se contó con una pequeña flota capaz de enfrentar los inminentes peligros que se avecinaban, debido a un posible contraataque llevado a cabo por España y Perú para recuperar los antiguos territorios perdidos. Algunos elementos realistas mantenían su actividad en la zona del Biobio, donde se habían replegados las tropas tras la victoria de Chacabuco, quienes se habían mantenido fuertes tras el intento de toma del puerto de Talcahuano, el cual significó la derrota chilena ante la falta de planificación frente a un sistema de fuertes interconectados que fueron aprovechados por los defensores. Por otra parte, en Inglaterra, se estaba negociando la contratación de sir Thomas Alexander Cochrane, uno de los mejores oficiales británicos de su época, quien se encontraba sin empleo en ese momento.

$4 \quad$ Armada de Chile. Escuadra Nacional 1818 - 2018, 51 


\section{España tras Napoleón}

Mientras tanto, la situación de España no estaba en óptimas condiciones, debido a los constantes años de guerra que los había enfrentado entre otros a Francia e Inglaterra, a Rusia por el dominio de la orden de Malta - que no terminó en ningún enfrentamiento ${ }^{5}$ - y luego la invasión de Napoleón en tierras ibéricas, que facilitaron la instalación de las Cortes liberales en Cádiz llevando a cabo su propia guerra de Independencia contra el invasor francés. Esto había minado la presencia de España dentro del sistema europeo, donde las grandes vencedoras fueron Inglaterra y Rusia, que lograron enfrentarse a Napoleón y vencerlo en Waterloo, consolidándose como las potencias del momento. El Congreso de Viena, que había ordenado las fronteras en Europa, garantizó la vuelta de las monarquías absolutistas, instalándose nuevamente Fernando VII, aunque para España no significó ganancias territoriales ni apoyo para recuperar los territorios de América, por lo que debió buscar su propio financiamiento y organización en tales empresas, como también posibles apoyos de los vencedores para tales objetivos.

Ante esta situación, el rey Fernando VII decide solicitar ayuda al zar Alejandro I de Rusia, por medio del embajador Tatischev - que se encontraba en la corte española desde 1808 - quien logra llegar a un acuerdo para la compra de barcos que integrasen la Escuadra Española, que sería enviada a Sudamérica como parte de plan de reconquista encabezado desde el Perú. Este acuerdo, llamado Eguía - Tatischev (1817) buscaba no solo la compra de nuevos navíos, sino que implicaba la injerencia rusa en los asuntos americanos, algo que no logró conseguir de manera efectiva, ya que se colocó en la palestra al propio rey, que compró los barcos a espaldas de sus ministros e influenciado por sus cercanos, la llamada "camarilla" que lo rodeaba y donde el propio Tatischev era miembro cercano de ella:

"No tardó en incorporarse a la camarilla y ejercer gran influencia con desdoro del Soberano que representaba, el bailío -Caballero de la Orden

5 Antonio Alemparte, "La Escuadra Rusa vendida por Alejandro I a Fernando VII en 1817”, Cuadernos Monográficos del Instituto de Historia y Cultura Naval No 36 (2001). 
de Malta ruso Tatischev; tuvo la destreza suficiente para persuadir a nuestro Rey de las ventajas de su íntima alianza con Rusia para sostener su Gobierno absoluto. Bajo sus auspicios, el "Deseado" entabló una cordial correspondencia con el Emperador que sirvió para mantener la influencia rusa predominante en este reinado. El marqués de las Amarillas, que lo trató personalmente en distintas ocasiones, afirma, en sus Recuerdos, que fue él quien engañó al Rey en el Convenio de los barcos"'.

Bajo la influencia de sus cercanos y de Tatischev, se llevaron a cabo las conversaciones para la compra de la flota rusa. El tratado en cuestión se firmó en pésimas condiciones para España, ya que comprometía el pago de dinero proveniente de Inglaterra por la abolición del tráfico de esclavos negros, pero sin dejar en claro las sumas posteriores, lo que beneficiaba claramente a los rusos ${ }^{7}$. Sin embargo, las discrepancias en torno a la compra de la flota rusa siguieron presente, ya que algunos señalaban que se encontraban en mal estado, a pesar de que los dos barcos que se encontraron en malas condiciones fueron reemplazados por otros nuevos tras los avisos respectivos ${ }^{8}$. Esto llevó a cimentar el mito que la flota se hallaba en pésimas condiciones - no considerando que si se envió material nuevo en su reemplazo - y que el tratado no había sido realmente efectivo para los fines de España, debido a que:

"La bibliografía española de autores de pensamiento liberal, (como el libro de Saralegui y Medina, también el de Bayo) es unánime en su juicio; resentidos con el antiliberalismo de Fernando VII, considera la compra como una estafa rusa a la camarilla del rey, camarilla demonizada también por ejercer una represión terrible al liberalismo. No cuentan que Alejandro I envió tres fragatas para sustituir al navío y la fragata que la inspección había declarado inservibles, y por tanto siguen contando el navío y la fragata inútiles dentro del horrible negocio".

6 Antonio Alemparte, La Escuadra Rusa, 38.

7 Antonio Alemparte, La Escuadra Rusa.

8 Agustín Barroso, España en la formación del sistema internacional post napoleónico (1812 - 1818) (Madrid: Universidad Complutense de Madrid, 2009)

9 Agustín Barroso, España en la formación, 154. 
Algunos autores hacen mención de esta situación, en donde se habla de la poderosa escuadra, pero de las pésimas condiciones en las que se encontraban al momento de entrar en servicio de la corona española:

"Componíase la escuadra, comprada a buen precio al emperador Alejandro, de 5 navíos de línea de 74 cañones y 3 fragatas de 44, pero resultó que apenas entregados los barcos en Cádiz sólo podían servir un navío y una fragata, por hallarse podridas las maderas de los demás"10.

Las adquisiciones de los nuevos barcos rusos completaron una considerable cantidad de naves a la escuadra, la que se encontraba muy debilitada desde las guerras enfrentadas en los inicios del siglo XIX, pero de las nuevas embarcaciones se especulaba que los ministros no habían desechado el acuerdo, por temor a las represalias del rey. Las unidades, divididas en navíos y fragatas, fueron rebautizadas a su llegada a la península, siendo las siguientes:

\section{Cuadro No. 1}

\begin{tabular}{|l|l|l|}
\hline \multicolumn{1}{|c|}{ TIPO } & \multicolumn{1}{|c|}{ NOMBRE RUSO } & \multicolumn{1}{c|}{ NOMBRE ESPAÑOL } \\
\hline NAVIO & DRESDE & FERNANDO VII \\
\hline NAVIO & NEPTUNO & ALEJANDRO I \\
\hline NAVIO & NORDADLER & NUMANCIA \\
\hline NAVIO & LUCKBECK & ESPAÑA \\
\hline NAVIO & TRES OBISPOS & VELASCO \\
\hline FRAGATA & MERCURIO & MERCURIO \\
\hline FRAGATA & PATTVIK & REINA MARIA ISABEL \\
\hline FRAGATA & ASTROIL & ASTROLABIO \\
\hline
\end{tabular}

Fuente: Barroso, Agustín. España en la formación del sistema internacional post napoleónico (1812 - 1818). Madrid. Universidad Complutense de Madrid. 2009, p. 154

Una de estas nuevas adquisiciones era la fragata María Isabel, fabricada en madera de abeto en los astilleros rusos del Mar Báltico, había sido botada en 1816 con el nombre de Patricio o Pattvik y tenía 1220 toneladas, aunque autores españoles hablan de su posible construcción

10 Alfredo Opisso, Miquel Oliver y Federico Rahola y Tremols, Historia de España y las Repúblicas latinoamericanas, Tomo 19 (Barcelona: Gallach, 1925), 204. 
en $1812^{11}$. Sin duda era una fragata nueva, con una capacidad de artillería de 50 cañones de 9 y 18 libras, por lo que la visión de los barcos rusos en mal estado - que ya se ha señalado - no se condice con la verdadera situación de este, que se encontraba en excelentes condiciones de navegar en su viaje a América. Por ello, con la llegada de los elementos necesarios, España lanzó una contraofensiva para sofocar no solo los nuevos gobiernos en América del Sur, sino que también atacar a todos aquellos que realizando acciones mediante patente de corso ahogaban el tráfico marítimo hacia la península, que era uno de los métodos utilizados por los nacientes estados para conseguir fondos. Se ordenó una expedición cuyo mando recayó en la fragata María Isabel, comandada por el Capitán de Navío Manuel del Castillo, desde donde:
"El 21 de mayo de 1818 zarpó de Cádiz al Callao, integrando la "Expedición de la Mar del Sur" y escoltando un convoy de once transportes que llevaba dos batallones de infantería del Regimiento "Cantabria" al mando del Teniente Coronel Fausto del Hoyo, tres Escuadrones de Caballería y dos Compañías de zapadores y artilleros, totalizando 2080 soldados, municiones, pólvora, cañones y numeroso avituallamiento, para reforzar el ejército español en el Perú" ${ }^{\prime 12}$.

Esta era una de las expediciones más grandes realizadas en su época, considerando la escasez de recursos que contaba la Corona española, pero más aún, la cantidad de tropas movilizadas para enfrentar los problemas de las Provincias Unidas del Rio de la Plata y en Chile consolidando sus efectivos para reforzar a las fuerzas del Perú. El zarpe se realizó en 21 mayo de 1818, un mes y medio después de la batalla de Maipú, donde las fuerzas realistas fueron derrotadas por los patriotas, escapando el general Mariano Osorio a Talcahuano con los restos de su ejército.

\section{Talcahuano: 28 De OCTUbre de 1818}

La flota española se dirigió a América, aunque el primer traspié la detuvo en las islas Canarias, donde producto de una parálisis es desem-

11 Antonio Alemparte, La Escuadra Rusa.

12 Fragata O'Higgins 1. Armada de Chile. Disponible en https://www.armada.cl/armada/tradicion-e-historia/unidades-historicas/o/fragata-o-higgins-1u/2014-02-14/150550.html 
barcado el Comandante del Castillo, quedando a cargo el Teniente de Navío Dionisio Capaz. Este debió enfrentar una serie de dificultades en el largo viaje, ya que por las diferencias propias de tonelaje, los navíos se distanciaron entre sí, e inclusive, se produjo la rebelión y huida del transporte Santísima Trinidad, que se dirige a colaborar con las autoridades de Buenos Aires, quienes informan al gobierno chileno de la nueva flota española. Mientras tanto, el gobierno de O’Higgins estaba preocupado de articular una Escuadra capaz de liberar al Perú y consolidar la Independencia, ya que entre otros, se debía completar totalmente el objetivo, cimentar la emancipación que se había logrado tras la batalla de Maipú. Tras la derrota, los españoles se concentraban en el sur, donde eran apoyadas por mapuches, siendo necesario el control de todo el territorio y de este modo, cortando las comunicaciones de los realistas.

Para ello, y con noticias de que la Expedición de la Mar del Sur se acercaba en dirección a Chile, Bernardo O’Higgins se conformó la Primera Escuadra Nacional, integrada por el Lautaro, San Martín, Chacabuco y Araucano con el fin de capturar el convoy español ${ }^{13}$. Su misión era interceptar las tropas, evitando que el poder de España se fortaleciera. El 10 de octubre de 1818, la Escuadra partió al sur, donde O’Higgins los despide con las siguientes palabras:

"Al dirigirme a los jefes, oficiales y tropa a cuyo valor y patriotismo confía el Estado de Chile la primera Escuadra de hombres libres, percibe mi corazón las más felices emociones en el presentimiento del magnífico cuadro que vais a presentar al mundo. Vuestro amor a la gloria no necesita ser estimulado con los recuerdos de los triunfos adquiridos tantas veces en tierra por vuestros ejércitos. Preparaos, pues, a afianzar, el imperio del Pacífico al que es llamado Chile por su situación geográfica y por el valor y heroísmo patriótico de sus hijos: ellos os colmarán de bendiciones a vuestro regreso, y el tributo que recibiréis de la gratitud nacional, igualará al que de antemano os ofrece vuestro compatriota Bernardo O’Higgins"14.

14 Enrique Larrañaga, "Bernardo O’Higgins, forjador del poderío marítimo de Chile”, Revista Libertador O’Higgins. Vol. 1 (2010): 425. 
Al mando de la Escuadra quedó Manuel Blanco Encalada en calidad de Capitán de Navío, quien al mando de sus hombres se dirigió al sur y por cuestiones propias del mal tiempo, demoraron su llegada. En Talcahuano las tropas españolas llegaban, siendo recibidas por el comandante Sánchez, mientras otros tantos se trasladaban al Callao directamente para unirse a las fuerzas del Virreinato. Mientras tanto, la flota chilena se detuvo en la isla Santa María, donde se obtuvo el documento para las señales de ingreso a Talcahuano - debido a que al enarbolar bandera española los soldados realistas que habían quedado allí se confundieron, pensando que se trataba de parte del convoy español, siendo capturados - recabándose la información clave para los movimientos en la bahía, por lo que Blanco Encalada se dirigió a Talcahuano con la seguridad de conocer las señales de la expedición española. En esta situación, se produce lo siguiente:

"La fragata María Isabel había recalado en Talcahuano el 24 de octubre de 1818 precedida por tres transportes. El coronel Juan Francisco Sánchez, jefe militar realista de Concepción, concibió la idea de utilizar estas tropas para iniciar una nueva campaña contra los independentistas. Pero en la mañana del 28 de octubre, los vigías observaron el paso frente a la Boca Chica, uno de los accesos a la bahía de Concepción, de dos grandes buques que ingresaron enseguida por la Boca Grande enarbolando el pabellón británico. Eran el navío San Martín y la fragata Lautaro" $"$.

Ese día, 28 de octubre de 1818, llegaban a la bahía de Concepción el San Martín y la Lautaro, dispuestos a dar caza a los españoles, por un costado de la isla Quiriquina, ante lo cual la María Isabel se aprestó para la defensa del puerto. Se inicia entonces el denominado "combate de Talcahuano" en donde la María Isabel se enfrentó a las dos naves chilenas. Con el paso de las horas, y las dificultades propias del terreno, su comandante observó que ante la desventaja en que se encuentra y muy cercano a la costa, decidió abandonar la nave con la mayor parte de la tripulación posible quedándose 60 fusileros y varando finalmente en el sector de la isla de los Reyes - actual Rocuant - uno de los puntos

15 Armada de Chile. Escuadra Nacional 1818 - 2018, 58 
más bajos de la costa de la bahía de Concepción, tras lo cual, arrió su bandera.

El Capitán Blanco Encalada decide encargar a los tenientes Bell y Crompton la toma del buque, consiguiéndose con éxito, no así sacar la nave, que se encontraba encallada, moviendo más tropas para soltarla de los bancos de arena que la inmovilizaban en ese momento. El combate se extiende hasta la noche, entre los patriotas que defienden su nueva adquisición y los realistas que intentan recuperarla, pasando la madrugada entre el fuego de los fusiles y la artillería de los fuertes cercanos. Solo a las 11 de la mañana del día siguiente, 29 de octubre, cuando empieza a soplar el viento, los patriotas logran desencallar y sacar la fragata gritando "Viva la Patria". Los españoles en cambio perdieron la nave capitana de la expedición y poco después, varios transportes con auxilios para el Perú fueron capturados por las fuerzas chilenas:

El 10, 12 y 14, respectivamente, de noviembre, fueron capturados en la isla Santa María los transportes españoles "Dolores", "Magdalena" y "Helena". El 18 de noviembre la "Chacabuco" capturó a los transportes "Carlota" y "Jerezana"16.

El optimismo y la alegría inundan a los patriotas, ya que en esa rápida expedición, no solo se obtienen transportes para la nueva flota sino que también uno de los mejores barcos que había llegado desde Europa. Uno de los primeros en enviar sus saludos al Director Supremo Bernardo O’Higgins es el comandante Blanco Encalada, que se comunicaba el 05 de noviembre desde la isla Santa María con las siguientes palabras:

"Mi venerado general: Con mi ayudante de órdenes remití á V. E. el sombrero y espada que se me dijo eran del comandante de la fragata María Isabel, felicitándome de haber podido cumplir á V. E. mi palabra, y unas cruces de Isabel la Católica y Luis XVIII, que se han encontrado en la fragata. (...) Yo felicito a V. E. (por) nuestro feliz ensayo como

16 Gustavo Jordán, “Creación de la Armada Nacional”, Revista de Marina No. 1 (2008): 47. 
autor de esta obra y a mí mismo por haber podido corresponder de algún modo a la confianza con que V. E. me honró"17.

Esto demostró que el comandante de la nave, Dionisio Capaz, escapó dejando la nave y sus propios implementos - como su espada -que fueron tomados como trofeos, pero además, se perdió la oportunidad de reforzar a las tropas realistas en América perdiendo importantes elementos de la flota que vino a enfrentar a los diferentes focos de resistencia patriota.

\begin{abstract}
"No llegando el auxilio de tierra, con ocho cañones que podía servir la gente rompió el fuego la fragata por breve tiempo; cuando los enemigos estuvieron encima, picó el cable del Norte, cazó la sobremesana en facha y se dejó ir hacia tierra, varando, bajo los disparos de ambos bajeles. Capaz mandó arriar la bandera, y se fue a tierra con tocia la gente que admitía el bote. Estaba la marea baja por suerte de los chilenos asaltantes, que eran el navío San Martín y la fragata Lautaro; a la creciente consiguieron poner a flote a la María Isabel, y llevársela como trofeo, de que no poco se envanecieron"18.
\end{abstract}

Sin duda, este hecho de armas constituyó un gran triunfo para las tropas, que debiendo enfrentar difíciles condiciones, logró capturar una fragata completa encallada en la arena para transformarla en parte importante de la flota chilena, reforzando sus fuerzas y en buenas condiciones para resistir los embates que llegaran desde el Virreinato del Perú, en donde había llegado el resto de las tropas. Por ello, se puede comprender que para la Armada de Chile:

"En su primera confrontación bélica, a fines de octubre de 1818, se cubrió de gloria al desbaratar un importante convoy español que navegaba a reforzar al Virreinato del Perú, capturando en Talcahuano

17 Benjamín Vicuña Mackenna, El almirante don Manuel Blanco Encalada: correspondencia de Blanco Encalada y otros chilenos eminentes con el Libertador (Madrid: Editorial América, 1917), 29.

18 Cesáreo Fernández Duro, Armada Española: desde la unión de los reinos de Castilla y León. Tomo 9. (i. e. Aragón) (Madrid: Establecimiento tipográfico Sucesores, 1893 - 1903), 192. 
la poderosa fragata "M. Isabel” y a la mayoría de los transportes con sus valiosos pertrechos"19.

Para los especialistas españoles, esta expedición fue considerada una de las peores llevadas a cabo, ya unida a las tropas existentes se podría haber cambiado el curso de los hechos en favor de España:

"Reconociéndola nuestros historiadores de la época, lamentaban el desastre de una expedición que, unida a las tropas del brigadier Osorio, en la provincia de Concepción, a su juicio, hubieran con toda probabilidad podido reconquistar el reino de Chile, asegurar la futura tranquilidad del Perú y aun concurrir con su ejército real a mayores y muy importantes empresas, mientras que, deshecha, prescindiendo del efecto moral, restaba a la escuadra española el bajel de mayor fuerza, sumándola a la que ya tenían los chilenos, amén de los pertrechos, de las armas, de las municiones, de los transportes y aun de los cascos de éstos" 20 .

\section{Consecuencias de la captura}

Las consecuencias ante tales hechos no se hicieron de esperar, en especial alabando las acciones de la captura de la fragata. En la Gaceta Ministerial, el 09 de noviembre de 1818, se mostraba en extenso la carta del comandante Blanco Encalada enviada a las autoridades nacionales en donde decía lo siguiente:

"Hemos abatido el orgullo de nuestros enemigos en las gloriosas acciones de Chacabuco y Maipú. Nos faltaba para coronar nuestros triunfos el ser dueños del Mar del Sur. Salió nuestra escuadra el 09 de octubre último, y ya nos ha facilitado ese predominio, apresando a la fragata española Reina María Isabel, de 50 cañones"21.

19 Washington Carrasco, “O’Higgins y la Expedición Libertadora al Perú”, Revista Libertador O’Higgins Vol. 1 (2010): 362

20 Cesáreo Fernández Duro, Armada Española, 193

21 Gaceta Ministerial de Chile, 09 Noviembre 1818 
La alegría no se hizo esperar, y al día siguiente se publicó un extenso detalle de las acciones ocurridas entre el 28 y 29 de octubre, que destacó la habilidad de los marinos para obtener una nave de esas características. Este hecho marcó el punto de inflexión en lo que pudo haber sido una gran ofensiva, ya que solo una parte del convoy llegó finalmente al Callao. Las acciones de Talcahuano marcó las noticias de la Gaceta Ministerial de Chile, medio de difusión oficial chileno, donde el Capitán Blanco Encalada mencionó lo siguiente:
"Este ha sido el ensayo de la Marina de Chile, obra de V. E. Espero que en lo sucesivo ella sabrá merecer más y más la confianza de los pueblos, que prestan sus servicios para sostenerla"22.

Con ello, se demostró la importancia de la captura de la fragata, que significó reforzar la idea de la independencia para el reciente gobierno, y demostró que existían capacidades de defensa suficientes para el territorio. En uno de los documentos claves que sigue la pista del devenir de los primeros años de la Armada, el denominado Manual del Marino (1817), se estableció los premios por la obtención de la fragata en combate, por medio de una insignia que se colocaba en adelante en los uniformes, mencionando la victoria de ese combate, pero además en el mismo documento, se alaba por lo demás la acción de la Armada:

\begin{abstract}
"Cuando el virtuoso pueblo de Chile se lisonjea de haber visto el primer ensayo de nuestra Escuadra Naval con el apresamiento de la fragata de guerra española Reina María Isabel, y de cinco transporte de tropas que nos conducían a la desolación y la muerte, adquirido el triunfo de los grandes sacrificios que ella le ha costado, no puede ser el Gobierno indiferente al mérito de los bravos, cuya intrepidez ha dado a nuestro pabellón el dominio del Pacifico y le prepara el respeto de las naciones, y la gloria de uniformar el sistema de la libertad al sur"23.
\end{abstract}

Este premio, presente en los uniformes de oficiales y tripulación, despertó gran interés en Chile. Por otra parte, la nueva fragata, integrada

22 Gaceta Ministerial de Chile, 10 de noviembre de 1818

23 Ministerio de Marina. Manual del Marino. Recopilación de leyes, decretos, reglamentos y órdenes de carácter general referentes a la Marina Chilena. Tomo I 1817 - 1866. Santiago (s. e). 1888, 47 
a la Armada como parte de sus unidades, llegó a Valparaíso ${ }^{24}$ recibió un nuevo nombre por ley en diciembre de 1818, cambiando de Reina María Isabel a O’Higgins, siendo pieza fundamental en la Expedición Libertadora al Perú, ya que se transformó en nave capitana de la misma, comandada por Lord Cochrane. Pero en España y Perú, dicho combate generó consecuencias tanto para su capitán como las acciones posteriores que se pensaban ejecutar en América.

Las autoridades españolas consideraron un desastre la pérdida de la fragata y de una serie de transportes de refuerzos, noticia que recién llegó el 02 de marzo de 1819, como lo explica el marqués de Casa Irujo:

"Acabo de recibir, por el Brasil, la confirmación indubitable del apresamiento de la fragata Isabel y tres transportes más, en el puerto de Talcahuano, evacuado antes por las tropas del Rey, a donde se metieron equivocadamente al ver tremolar la bandera del Rey. Los resultados de este desgraciado accidente, sea con relación a la opinión pública que tiene tanta influencia, sea por la seguridad del Perú, pueden ser incalculables. No he dado todavía cuenta a S.M. de estas melancólicas noticias, a consecuencia de las cuales me parece sería muy propio: que sin perder un momento nos juntásemos para tomar en consideración el estado de las cosas en el Mar del Sur y consultas sobre las medidas que podrían adoptarse en el estado presente de las cosas. Tenga Vm. la bondad de hacerme saber sus intenciones por el portador, pues esta noche tengo despacho y me es preciso informar a S.M. de esta ocurrencia" 25.

Mientras tanto, al capitán Dionisio Capaz se le siguió un sumario debido a sus acciones, en especial por el abandono de la fragata y su captura por los marinos chilenos, juicio que se realizó hasta 1820. El proceso fiscal, realizado por el capitán de fragata Joaquín Bocalan determinó que quedaba absuelto, ya que en la deplorables condiciones de la nave le impidieron hacer algo más, e inclusive menciona "el malísimo estado, tanto militar como marinero, de la fragata María Isabel a su salida de

24 Benjamín Vicuña Mackenna, Los pañales de la Marina Nacional (Valparaíso: Imprenta y Librería L. de la Cruz, 1904).

25 Antonio Alemparte, La Escuadra Rusa, 109. 
Cádiz"26, como a su vez no tener gente suficiente para enfrentar al enemigo, una situación que por lo menos resulta curiosa al alero de las circunstancias, en donde el capitán abandonó la nave perdiendo incluso su espada y sombrero. También se presentó como excusa el estado de la flota rusa, el desconocimiento del poder de fuego del puerto de Talcahuano, además del pésimo estado de la tripulación al momento de su llegada a ese puerto, enferma de escorbuto, que le impidió el uso de sus fuerzas. En cuanto a la nave, dichas explicaciones no concuerdan con la descripción del propio Blanco Encalada cuando habla de las condiciones de la fragata:

"Mi querido amigo. La Reina María Isabel, que tantos suspiros nos ha costado, está en mi poder; es hermosísima, y de un andar admirable; en la Mar del Sur no hay buque que ande con ella y con dificultad en el mundo. En su diario desde Cádiz tiene hora de trece millas y media, andar que jamás he oído desde que sirvo en la Marina; al famoso bergantín Araucano y corbeta Chacabuco los deja con la misma facilidad que ellos a la Lautaro; su artillería es divina, tiene dos años, desde que salió de Cádiz no ha hecho una gota de agua y esta ricamente pertrechada"27.

Con ello, se puede observar que el equipamiento de la nave eran excelentes, una verdadera pieza de valor que adquirió Chile con su captura, algo que España intentó disminuir con un proceso donde absolvió al capitán alegando malas condiciones de la fragata, enfermedad de la tripulación (escorbuto) y que el resultado del combate solo respondía al deplorable estado de la misma. Con la captura de la nave y de los transportes, las acciones del Perú no se reforzaron, se aisló a los grupos armados que se resistían en el Biobio, pero lamentablemente las disputas se prolongaron por una década más, en el periodo de la Guerra a Muerte. Por ello:

"La importancia de esta primera operación exitosa de la Escuadra recién formada reside en que el gobierno sintió confianza para emprender

26 Joaquín Bocalán, Conclusión fiscal en el proceso sobre la pérdida de la fragata Reina María Isabel, su Comandante el teniente de navío de la R. Armada, D. Dionisio Capaz por el capitán de fragata, D. Joaquín Bocalán, fiscal de esta causa. 1820 Disponible en http://bdh-rd.bne.es/viewer.vm?i$\mathrm{d}=0000198627$ \&page $=1$

27 Gaceta Ministerial de Chile, 10 de noviembre de 1818. 
una campaña contra el virreinato. Asimismo, resultó muy meritorio el hecho de que unos bisoños elementos locales combatieran con singular prestancia apoyándose en la experiencia de los extranjeros. También es digno de destacar el comandante en jefe, Manuel Blanco Encalada, por su atinada resolución de los conflictos, que podrían haberse exacerbado en las heterogéneas dotaciones y por el hecho de mandar a comandantes con mucha mayor experiencia. Blanco superó este desafío gracias a su cultura, su superior preparación profesional y su incuestionable entrega a la causa de la independencia"28.

Luego de este hecho, las condiciones mejoraron para Chile, ya que se pasó de un estado de incipiente peligro a sus costas, a mares seguros debido a los aportes del gobierno a una nueva institucionalidad y la creación de una flota que se incrementó con la captura de la fragata María Isabel. Tras ello, se creó la Expedición Libertadora, cuyo fin sería acabar con el Virreinato del Perú consolidando la independencia de América del Sur. Por otra parte, la situación peninsular no era satisfactoria:

"Tal fue el fin de esta famosa expedición que había zarpado de la península ufana y confiada en el buen suceso, así como la armada invencible de Felipe II. Doscientos hombres sublevados en la Trinidad, 800 desembarcados en Talcahuano, 700 caídos en poder de los insurgentes y como 400 que perecieron en la travesía, completaban el monto de las tropas con un destino fatal" 29 .

Esto significó un importante golpe a los intereses españoles, debido a que la expedición era muy relevante en los planes de reconquista americana. Mientras tanto, la fragata María Isabel, que como se ha mencionado anteriormente, fue bautizada como O’Higgins ${ }^{30}$, cumplió importantes labores en el proceso independentista desarrollado por Chile en el Pacífico.

29 C. M Sayago, Crónica de la Marina Militar de la República de Chile (Copiapó: Imprenta La Unión, 1864), 31

30 Senado Conservador. Sesión 24 extraordinaria en 09 de diciembre de 1818. Disponible en https:// www.bcn.cl/obtienearchivo?id=recursoslegales $/ 10221.3 / 31467 / 1 /$ S_18181209.pdf 


\section{Conclusiones}

La Independencia de Chile trajo consigo una serie de disyuntivas para afrontar la defensa del territorio ante posibles ataques e invasiones españolas. Para ello, fue necesaria la creación de un poder naval capaz de disputar el control de las rutas marítimas y de frenar cualquier avance que por esta vía se dirigiese al país, que fuese realmente efectivo y no solo un intento como había ocurrido en 1813, donde la pérdida del mar trajo consigo la reconquista. El Director Supremo Bernardo O'Higgins, supo comprender la vital importancia de la Armada en un país recién independizado, para ello consiguió establecer las primeras ordenanzas y decretos de la nueva institución como obtener los primeros buques ante el inminente ataque que desde España podría caer en el Cono Sur, es decir, por medio de este trabajo se comprende la historia marítima en el contexto de la historia institucional ${ }^{31}$.

Mientras tanto, en España se estaba organizando una gran expedición con el fin de apoyar al Virreinato del Perú, tras años de conflicto que los habían debilitado en el concierto del poder europeo, y del cual no había obtenido mayores resultados tras el Congreso de Viena en 1815. Al mando de esta Expedición, estaba la recientemente adquirida fragata Reina María Isabel. Esta unidad llamaba poderosamente la atención, ya que era nueva y se había obtenido en un acuerdo conjunto entre el rey Fernando VII y el zar Alejandro I de Rusia, en donde este último le cedía una numerosa cantidad de naves para levantar su Armada. Un resultado anexo era conseguir el apoyo ruso en las labores de recuperación de América, algo que no se logró obtener, ya que solo se consiguió las naves, surgiendo serias dudas en torno a su estado y si fueron pagadas definitivamente o no por las autoridades españolas. Las tropas salieron desde Cádiz y la fragata quedó en manos de Dionisio Capaz, teniente de navío que reemplazó al comandante por enfermedad de este.

Las labores atentas en Chile permitieron enfrentar esta incursión armada, enviando la Escuadra al sur para interceptar los barcos enemigos,

31 Carlos, Martínez S., "La historia marítima de los tiempos modernos. Una historia total del mar y sus orillas". Drassana No. 22 (2014). 
comandada por el capitán Manuel Blanco Encalada, cuyo fin era evitar la llegada de los refuerzos tanto a los realistas atrincherados en el Biobio como en el Perú. El 28 de octubre de 1818, la fragata María Isabel se enfrenta al San Martin y Lautaro en Talcahuano, donde finalmente es capturada por los chilenos. Aunque desvarar la nave costó un día más y ante el fuego incesante de los realistas, finalmente la nave capitana de la expedición fue llevada por los patriotas al grito de "Viva la Patria". La noticia recorre el país, ante la alegría de las autoridades que ven más cerca la consolidación de la libertad, siendo esta un importante impulso para el nuevo gobierno que se había instalado.

En Chile y España las consecuencias son dispares. Mientras en Chile se mencionó la victoria en documentos oficiales, tanto en el Manual del Marino y en la Gaceta Ministerial, recalcando las condiciones de la fragata recién capturada, según los escritos de Blanco Encalada, la perdida para España significó un duro revés en los planes de la expedición que se estaba proyectando, ya que llegó con menos elementos (fragata y transportes) al puerto del Callao, en Perú. Tras esto, Chile comienza a proyectar la Expedición Libertadora al Perú, para terminar con el poder de los realistas en América del Sur y consolidar a los nuevos estados. Por otra parte, las autoridades españolas cierran el caso absolviendo al capitán de su actuación en combate debido al mal estado de la fragata y de su tripulación, creando desde entonces el prejuicio de los barcos rusos, como una pésima compra realizada por Fernando VII y que significó la perdida de barcos y el fracaso de la expedición, sin realizar la autocrítica de las malas decisiones de sus comandantes. Sin duda, la toma de la fragata María Isabel constituye un éxito para Chile, un ejemplo de la relevancia que contiene el poder naval para consolidar la libertad de un naciente país sudamericano.

\section{Bibliografia}

\section{FUENTES PRIMARIAS}

\section{Archivo}

Bocalan, Joaquín. Conclusión fiscal en el proceso sobre la pérdida de la fragata Reina María Isabel, su Comandante el teniente de navío 
de la R. Armada, D. Dionisio Capaz por el capitán de fragata, D. Joaquín Bocalan, fiscal de esta causa. 1820. Disponible en http:// bdh-rd.bne.es/viewer.vm?id=0000198627\&page $=1$

Ministerio de Marina. Manual del Marino. Recopilación de leyes, decretos, reglamentos y órdenes de carácter general referentes a la Marina Chilena. Tomo I 1817 - 1866. Santiago (s. e). 1888

Senado Conservador. Sesión 24 extraordinaria en 09 de diciembre de 1818. Disponible en https://www.bcn.cl/obtienearchivo?id=recursoslegales/10221.3/31467/1/S_18181209.pdf

\section{Publicaciones periódicas}

Gaceta Ministerial de Chile. 09 de Noviembre de 1818.

Gaceta Ministerial de Chile. 10 de Noviembre de 1818.

\section{FuENTES SECUNDARIAS}

Alemparte, Antonio. "La Escuadra Rusa vendida por Alejandro I a Fernando VII en 1817”. Cuadernos Monográficos del Instituto de Historia y Cultura Naval No. 36 (2001).

Armada de Chile. Escuadra Nacional 1818 - 2018. Santiago: Ograma Editores, 2018.

Barroso, Agustín. España en la formación del sistema internacional post napoleónico (1812 - 1818). Madrid: Universidad Complutense de Madrid, 2009.

Carrasco, Washington. O’Higgins y la Expedición Libertadora al Perú. Revista Libertador O’Higgins Vol. 1 (2010): 361 - 368.

Fernández Duro, Cesáreo. Armada Española: desde la unión de los reinos de Castilla y León. Tomo 9. (i. e. Aragón). Madrid: Establecimiento tipográfico Sucesores, 1895 - 1903.

Fragata O’Higgins 1. Armada de Chile. Disponible en https://www. armada.cl/armada/tradicion-e-historia/unidades-historicas/o/ fragata-o-higgins-1u/2014-02-14/150550.html

Iturriaga, Jorge. Bernardo O’Higgins, Lord Cochrane y el Mar de Chile. Revista Libertador O’Higgins. Vol. 1 (2010): 355 - 360.

Jordán, Gustavo. “Creación de la Armada Nacional". Revista de Marina No. 1 (2008): 41 - 55. 
Larrañaga, Enrique. “Bernardo O’Higgins, forjador del poderío marítimo de Chile". Revista Libertador O’Higgins. Vol. 1 (2010): 419 $-427$.

Martínez S., Carlos. "La historia marítima de los tiempos modernos. Una historia total del mar y sus orillas". Drassana No. 22 (2014).

Opisso, Alfredo; Oliver, Miquel; Rahola y Tremols, Federico; Historia de España y las Repúblicas latinoamericanas. Tomo 19. Barcelona: Gallach, 1925.

Sayago, C. M, Crónica de la Marina Militar de la República de Chile. Copiapó: Imprenta La Unión, 1864.

Valenzuela, Renato. Bernardo O’Higgins. El Estado de Chile y el poder naval en la independencia de los países del sur de América. Santiago: Editorial Andrés Bello, 2008.

Vicuña Mackenna, Benjamín. El almirante don Manuel Blanco Encalada: correspondencia de Blanco Encalada y otros chilenos eminentes con el Libertador. Madrid: Editorial América, 1917.

Vicuña Mackenna, Benjamín. Los pañales de la Marina Nacional. Valparaíso: Imprenta y Librería L. de la Cruz, 1904.

Para citar este artículo: Manzano Iturra, Karen Isabel. "La captura de la fragata María Isabel. El dilema de los barcos rusos y la independencia de chile", Historia Caribe Vol. XVI No. 39 (Julio-Diciembre 2021): 263-286. DOI: https://doi.org/10.15648/hc.39.2021.2966 